\title{
Improving the Reliability and Ecological Validity of Pharmaceutical Risk Assessment: Turquoise Killifish (Nothobranchius furzeri) as a Model in Behavioral Ecotoxicology
}

\author{
Eli S.J. Thoré, ${ }^{a}$ Laure Steenaerts, ${ }^{a}$ Charlotte Philippe, ${ }^{a, b}$ Arnout F. Grégoir, ${ }^{a}$ Luc Brendonck, ${ }^{a, c}$ and Tom Pinceel ${ }^{a, d}$ \\ ${ }^{a}$ Animal Ecology, Global Change and Sustainable Development, KU Leuven, Leuven, Belgium \\ ${ }^{b}$ Systemic Physiological and Ecotoxicological Research, University of Antwerp, Antwerp, Belgium \\ Water Research Group, Unit for Environmental Sciences and Management, North-West University, Potchefstroom, South Africa \\ ${ }^{\mathrm{d} C e n t r e}$ for Environmental Management, University of the Free State, Bloemfontein, South Africa
}

Abstract: Pharmaceuticals are essential for human well-being, but their increasing and continuous use pollutes the environment. Although behavioral ecotoxicology is increasingly advocated to assess the effects of pharmaceutical pollution on wild life and ecosystems, a consensus on the actual environmental risks is lacking for most compounds. The main limitation is the lack of standardized reproducible tests that are based on sensitive behavioral endpoints and that accommodate a high ecological relevance. In the present study, we assessed the impact of a 3-wk exposure to the antidepressant fluoxetine on multiple behavioral traits in the promising new model organism Nothobranchius furzeri (turquoise killifish). Overall, our study shows that fluoxetine can impact feeding behavior, habitat choice in a novel environment, and antipredator response of $N$. furzeri individuals; effects on spontaneous activity and exploration tendency were less pronounced. However, effects became only apparent when individuals were exposed to fluoxetine concentrations that were 10 times higher than typical concentrations in natural aquatic environments. Ecotoxicologists are challenged to maximize both the reliability and ecological validity of risk assessments of pollutants. Our study contributes to the development of a time- and cost-efficient, standardized ecotoxicological test based on sensitive, ecologically relevant behavioral endpoints in N. furzeri. Environ Toxicol Chem 2018;9999:1-9. (C) 2018 SETAC

Keywords: Nothobranchius; Ecotoxicology; Behavioral toxicology; Emerging pollutants; Fluoxetine

\section{INTRODUCTION}

Pharmaceuticals are of high socioeconomic importance, and their use (especially that of antidepressants) has increased enormously over the past decades (Gusmão et al. 2013). They constitute a novel class of environmental contaminants ("emerging"; Dzieweczynski and Hebert 2012; Loos et al. 2013; Brodin et al. 2014). Many pharmaceutical compounds are continuously discharged through domestic wastewater and are (pseudo-) persistent in the environment (Fent et al. 2006; Arnold et al. 2014). Although environmental concentrations are often low compared with traditional contaminants, pharmaceuticals are typically highly potent and designed to trigger specific

This article includes online-only Supplemental Data.

* Address correspondence to eli.thore@kuleuven.be

Published online 25 October 2018 in Wiley Online Library

(wileyonlinelibrary.com)

DOI: $10.1002 /$ etc. 4301 pharmacological responses at low doses (Arnold et al. 2014). Pharmaceutical pollution is likely affecting aquatic wildlife because pharmaceutical products often target evolutionarily conserved pathways (Gunnarsson et al. 2008). Current ecotoxicity tests are generally designed to detect lethal, harmful, or stressful effects of exposure to traditional contaminants; they are less suitable for detecting specific pharmacological effects.

An improved assessment of the subtle effects of pollutants such as behavioral alteration is considered an essential step to gain an accurate estimation of the actual impact of pharmaceutical pollution on natural water bodies and their fauna (Fent et al. 2006; Brodin et al. 2014; Pyle and Ford 2017). Changes in behavioral expression have been shown to have direct (e.g. feeding rate, predator avoidance) and indirect (e.g. population dynamics, community structure) ecological consequences (Wolf and Weissing 2012; Brodin et al. 2014). In addition, because behavior is the integrative response to internal and external factors (Dell'Omo 2002; Levitis et al. 2009), it could be an 
especially sensitive tool for ecotoxicologists (Melvin and Wilson 2013; Brodin et al. 2014).

Fish are particularly suitable model organisms for assessing the environmental impact of pharmaceutical pollution. Because their neuromuscular physiology is similar to that of humans and because pharmacological target molecules are often highly conserved, there is a high probability that fish are affected by human pharmaceuticals (Gunnarsson et al. 2008; Sakowski et al. 2012). The turquoise killifish (Nothobranchius furzeri) is a promising new model in many different biological disciplines (Cellerino et al. 2015), mainly because of its extremely fast maturation $(<16 \mathrm{~d})$ and short generation time $(<3 \mathrm{mo})$. These traits enable $N$. furzeri to persist in temporary ponds with extremely short inundations in southeastern Africa (Cellerino et al. 2015; Polačik et al. 2016). Fast maturation likely trades off with lifespan: N. furzeri only lives for 5 to 6 mo under optimal laboratory conditions (Terzibasi et al. 2008; Wang et al. 2015; Polačik et al. 2016). This makes it an ideal model organism for whole-life studies and for studying aging-related processes. On reaching maturity, fish spawn daily and produce drought-resistant eggs that remain dormant in the sediment until the next inundation (Pinceel et al. 2015; Grégoir et al. 2017a). The fish produce large amounts of eggs that can easily be stored for up to several years and hatched synchronously for experimental purposes (Polačik et al. 2016; Grégoir et al. 2017b). Because of this unique trait set, $N$. furzeri has been introduced as a model species in traditional ecotoxicology (Philippe et al. 2017, 2018a-c). The available tools for $N$. furzeri, such as a whole-brain atlas (D'Angelo 2013), agerelated histopathological analyses, an annotated genome and transcriptome (Di Cicco et al. 2011; Reichwald et al. 2015; Valenzano et al. 2015), and the generation of transgenic lines have added to the value of $N$. furzeri as a model species in ecotoxicology. Furthermore, as the need to unravel the underlying physiological and biochemical mechanisms of behavioral expression is increasingly emphasized (Sloman and McNeil 2012; Parker 2016, Thoré et al. 2018), these tools could aid in the further advancement of behavioral ecotoxicology. The overall aim of the present study was to investigate the potential of $N$. furzeri as a model in behavioral ecotoxicology.

Fluoxetine is the active compound of Prozac and is used as a selective serotonin reuptake inhibitor with antidepressant and anxiolytic effects (Winder et al. 2012). At the moment, the compound is often present in surface waters at concentrations that average about $0.5 \mu \mathrm{g} / \mathrm{L}$ (Winder et al. 2012). These levels are expected to increase further because fluoxetine use is continuously increasing (Winder et al. 2012; Dzieweczynski et al. 2016b). Fluoxetine is a well-studied compound in pharmacology and ecotoxicology. Although reference background data on its targeted molecular mode of action are widely available (Brodin et al. 2014; Parker 2016), standard tests to assess its impact on the fauna of aquatic ecosystems are lacking. Tests based on sensitive behavioral endpoints could accommodate high ecological relevance and provide the means for time- and cost-efficient risk assessment of fluoxetine and other emerging pharmaceutical compounds.
In the present study we investigated the potential of $N$. furzeri for behavioral ecotoxicology studies. We performed a 3-wk experiment and assessed the impact of exposure to environmentally relevant fluoxetine concentrations on activity, boldness, and exploration; we also chose the endpoints of feeding behavior, habitat choice, and antipredator response as behavioral traits with more direct ecological relevance. We selected this set of traits because they all have known fitness implications for fish (Brodin et al. 2014). Fluoxetine treatment reduced spontaneous locomotor activity and induced anxiolytic responses in medaka (Oryzias latipes; Ansai et al. 2016) and reduced anxiety-related behavior in zebrafish (Danio rerio; Wong et al. 2013). Congruent with these findings and given the anxiolytic properties of fluoxetine, we expected fluoxetineexposed fish to exhibit less risk-averse behavior expressed as higher activity, boldness, and exploration levels, a high feeding rate, and a relaxed antipredator response.

\section{MATERIALS AND METHODS}

\section{General setup and fish maintenance}

The tested $N$. furzeri fish originated from a natural population in central Mozambique (MZCS-414). The laboratory population had been maintained for 3 generations under optimal common garden conditions prior to the onset of the experiment. Sixty-five experimental fish were hatched by inundating "ready-to-hatch eggs" (stage 43 sensu Wourms 1972) at $14^{\circ} \mathrm{C}$, according to the protocol of Polačik et al. (2016). Fish tanks were kept in a bain-marie system to ensure a constant water temperature $\left(24.3^{\circ} \mathrm{C} \pm 1.09\right.$ standard deviation [SD]) at a $14: 10$-h light:dark regime.

The present study was approved by the ethical committee of KU Leuven (file no. P160/2016). All procedures performed conform to the legal requirements for animal research in Belgium. Individual condition and health of the fish were checked multiple times a day by 2 researchers separately (E.S. J. Thoré. and L. Steenaerts). Water parameters were measured daily in each tank to keep track of water quality. Animals were housed under optimal conditions, and the hand-made air-driven filter provided shelter in all tanks. Disturbance and handling was kept to a minimum.

Starting at $2 \mathrm{~d}$ post hatch, fish larvae were housed in 4-L tanks in groups of 20 individuals; 2 wk after hatching, fish were transferred to 10-L tanks in groups of 10 individuals. After $3 \mathrm{wk}$, fish were housed individually for individual monitoring in 9-L tanks ( $49 \mathrm{~cm}$ long $\times 19 \mathrm{~cm}$ wide $\times 16 \mathrm{~cm}$ high) with an air-driven filter. Tanks were visually separated from each other with opaque plastic to exclude social contact among individuals. One housing compartment/tank was delimited $(\sim 12 \mathrm{~cm}$ long $\times 19 \mathrm{~cm}$ wide) to resemble the tank setup for behavioral testing (see below).

Following Organisation for Economic Co-operation and Development test guidelines 203 (1992) and 229 (2012), reconstituted water was used throughout the experiment by adding Instant Ocean salt mix to deionized water until a conductivity of $600 \mu \mathrm{S} / \mathrm{cm}$ was reached. Water was renewed every $2 \mathrm{~d}$ when larvae were housed in groups and once a week when fish were housed individually. This ensured good water 
quality while limiting handling $(\mathrm{pH}$ mean $\pm \mathrm{SD} 8.09 \pm 0.33$, ammonium $<0.2 \mathrm{mg} / \mathrm{L}$, nitrite $<25 \mathrm{mg} / \mathrm{L}$ ). When housed in groups, larvae were fed twice a day an ad libitum quantity of Artemia franciscana nauplii (Ocean Nutrition). Individually housed fish were fed ad libitum with Chironomus larvae (Ocean Nutrition) and twice a day with Artemia nauplii.

Starting at 4 wk post hatching, individual fish were subjected weekly to 4 behavioral tests, which were repeated every week for a total of 5 consecutive wk. The tests, which are explained in further detail below, included: 1) an emergence test, 2) a habitat choice test, 3) an open field test, and 4) a life skills test. For each test, each fish was transferred to an experimental arena, allowed to acclimate for $5 \mathrm{~min}$, and video recorded from above using a digital camera (Logitech C920 HD Pro Webcam). Recordings were manually analyzed afterwards (observer-blind), except for open field data, which were analyzed using EthoVision XT Ver 9.0 video-tracking software (Noldus Information Technologies). After each behavioral test, fish were transferred back to their respective housing tanks. To minimize behavioral variation due to diel activity changes and to add to the logistic feasibility of the experiment, each sampling burst was restricted to a maximum of $3.5 \mathrm{~h}$, and fish were randomly divided over 2 cohorts. Each cohort was subjected to 1 assay/d. Every Tuesday morning, the cohort 1 fish were subjected to the habitat choice test, and in the afternoon the cohort 2 fish were subjected to the emergence test. Every Wednesday, the cohorts 1 and 2 fish were subjected to the emergence test (afternoon) and the habitat choice test (morning), respectively. The same setup was repeated on Thursday and Friday, this time subjecting the fish to either the open field test or the life skills test. Fish were not fed for $24 \mathrm{~h}$ before the emergence and life skills test to stimulate exploration of the arena and to prevent disinterest in food. No behavioral tests were carried out on Saturday, Sunday, or Monday. Every Monday, water of the housing tanks was renewed.

At 6 wk post hatch (i.e., starting at the $3 r d$ wk of the 5 -wk test period), fish were randomly assigned to 1 of 3 treatments: F1, F2, and control. In the F1 condition (14 females, 9 males) fish were exposed to $0.5 \mu \mathrm{g} / \mathrm{L}$ fluoxetine hydrochloride (F-132; SigmaAldrich); in the F2 condition (11 females, 11 males) fish were exposed to $5 \mu \mathrm{g} / \mathrm{L}$ of the same compound. Because dimethyl sulfoxide (DMSO) was used as a solvent for preparation of the fluoxetine solution (see Preparation of solutions section), control fish ( 9 females, 11 males) were exposed to the same amount of DMSO as in the F2 condition (0.00001\%). Treatments were applied during each water exchange (i.e., on Monday).

During the 5-wk test period, body size (tip of snout to tip of tail, dorsal view) and body width (at the pectoral fins, dorsal view) to approximate fish condition were monitored every Monday by briefly transferring every individual to a Petri dish with a small amount of water. Top-view, size-calibrated photographs were taken and analyzed using the open source image processing software ImageJ Ver 1.50i (Schneider et al. 2012).

\section{Preparation of solutions}

Stock aliquots $(\mathrm{mL})$ were prepared by dissolving fluoxetine hydrochloride in DMSO to $500 \mathrm{mg} / \mathrm{L}$ and were preserved at -
$18{ }^{\circ} \mathrm{C}$ until use (maximum age $3 \mathrm{mo}$ ). Working standard solutions were prepared by thawing and diluting stock aliquots to $5 \mathrm{mg} / \mathrm{L}$ in fish rearing medium (reconstituted water at $600 \mu \mathrm{S} / \mathrm{cm}$ ) and preserved at $4{ }^{\circ} \mathrm{C}$. The DMSO working standard solutions were prepared by diluting DMSO with reconstituted water $(600 \mu \mathrm{S} /$ $\mathrm{cm}$ ) to a $1 \%$ solution, and preserved at $4{ }^{\circ} \mathrm{C}$.

Water samples were taken and analyzed for fluoxetine concentration in the last week of the test period on the 3rd and 5th $\mathrm{d}$ after administration. Actual concentrations of the F1 and F2 treatments on the 3rd and 5th d after administration, measured by liquid chromatrography-tandem mass spectrometry, were 0.37 (SD 0.17) and 4.41 (SD 0.90), and 0.32 (SD 0.21) and 4.47 (SD 0.93) $\mu \mathrm{g} / \mathrm{L}$, respectively.

\section{Behavioral tests}

Emergence test. The emergence test arena resembled the housing tank setup (Figure 1A). Fish were introduced to the smaller "start" compartment, after which a doorway was opened, allowing the individual to enter and explore the "novel" larger compartment during the next $45 \mathrm{~min}$. Latency time to enter the novel compartment as a measure of exploration tendency was recorded, and a maximum score of $45 \mathrm{~min}$ was assigned to fish that failed to enter the novel environment (33\% of all data points). In addition, the novel compartment was equally divided into a barren zone (risk-prone zone) and a zone holding artificial plants as shelter (risk-averse zone). Fish preference for the zones as a measure for risk aversion in this novel compartment (calculated as the amount of time spent in the barren zone compared with the total amount of time spent in the novel compartment) was recorded for $30 \mathrm{~min}$.

Open field test. In the open field arena (Figure 1B), spontaneous activity was recorded for $20 \mathrm{~min}$. Total distance moved was monitored as a measure of locomotor activity. Moreover, the open field arena was virtually divided into a centrum $(50 \%$ of arena length and width) and a peripheral zone. Activity in the centrum zone is considered more risk-prone behavior (boldness) compared with activity in the peripheral zone (Ansai et al. 2016). Thus the number of times the fish entered the centrum, the latency time to enter the centrum for the first time, and the cumulative duration spent in the centrum were assessed as a measure of boldness.

Habitat choice test. The habitat choice test arena was equally divided into a barren zone and a zone holding artificial plants for shelter (Figure 1C). Fish preference for the zones (calculated as the relative amount of time spent in the barren zone) was recorded for $30 \mathrm{~min}$.

Life skills test. Using a life skills test arena (Figure 1D), feeding behavior and antipredator response were assessed. The arena was virtually divided into 4 equally sized zones. When fish entered zone 1 or 4, Chironomus larvae were added in zone 3, and latency time to initiate feeding was assessed. Fish that did not feed within 15 min were given the maximum score of $15 \mathrm{~min}$. As soon as fish started feeding, a suspended 15-mL Falcon tube 
A

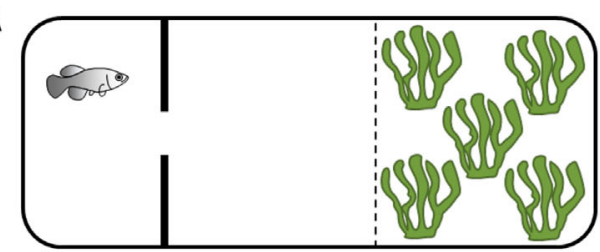

$\mathrm{C}$

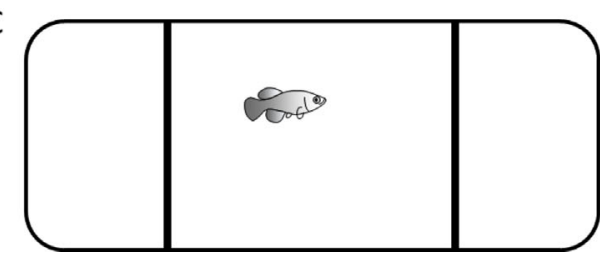

B

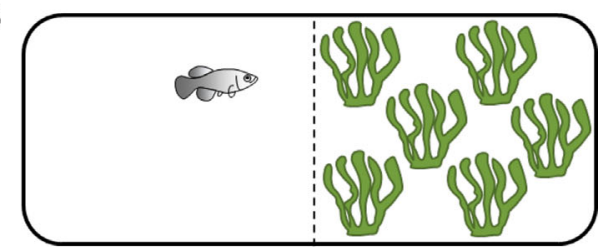

D

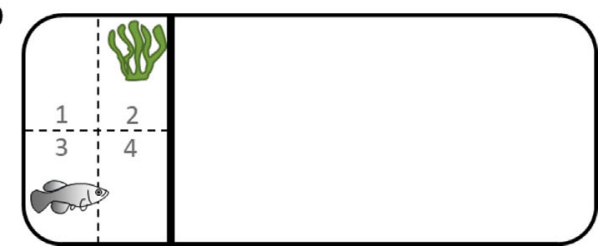

FIGURE 1: Schematic representation of the different test arenas used (dorsal view). All tanks are $\mathrm{L} \times \mathrm{W} \times \mathrm{H} 49 \mathrm{~cm}$ long $\times 19 \mathrm{~cm}$ wide $\times 16 \mathrm{~cm} \mathrm{high} \mathrm{and}$ hold $9 \mathrm{~L}$ of water, except for the open field arena, which only holds water to a height of $2 \mathrm{~cm}$. (A) Experimental setup for the emergence test. The start compartment resembles the housing conditions. A doorway (diameter $20 \mathrm{~mm}$ ) allows individuals to explore the novel, larger part of the tank that is equally divided into an open, barren part and a part provided with artificial plants as shelter. (B) Experimental setup for the habitat choice test. The tank is equally divided into an open, barren part and a part provided with artificial plants as shelter. The dotted line represents a virtual barrier. (C) Open field experimental setup. (D) Experimental setup for the life skills test, used to characterize feeding and antipredator behavior. The experimental compartment was virtually divided into 4 equally sized zones (delineated by the dotted lines). Zone 2 holds an artificial plant as shelter, whereas both feeding stimulus and simulated avian attack were applied in zone 3.

(weighted, opaque) was dropped and allowed to touch the water surface in zone 3 as simulation of an avian predator attack. The time until movement and the time needed to resume feeding for fish that froze or swam away were assessed. The test was terminated $45 \mathrm{~min}$ after the simulated predator attack. Fish that did not resume feeding were given the maximum score of $45 \mathrm{~min}$.

\section{Statistical analyses}

All statistical analyses were performed in $R$ 3.3.1 ( $R$ Development Core Team 2016) at a significance level of 0.05. Model assumptions including homogeneity of variance and distributional fit were verified graphically for all analyses. For all behavioral response variables, linear mixed models with Gaussian error distribution were fitted (Ime4 package) with treatment (control, F1, F2) and sex (male, female) as fixed factors. The interaction term between treatment and sex was nonsignificant for all models and was therefore excluded from the final models. Fish identity, trial number (referring to the repeated measures), and cohort were added to the model as random factors. Only behavioral responses after treatment were considered in the analyses (i.e., 3 repeated measures/individual), because the first 2 trials were used to habituate fish to the experimental setup. Condition of the fish was approximated by body width measurements corrected for body size and was analyzed using a linear mixed model with Gaussian error distribution with treatment, trial, and their interaction as fixed factors. Sex was added to the model as a predictor variable and fish identity as a random factor. Differences between groups were assessed using Wald chi-square tests (car package) and Tukey-corrected pairwise comparisons (Ismeans package). Behavioral response variables/behavioral test are given in Table 1, including the applied transformation to meet model assumptions.

\section{RESULTS}

\section{Emergence test}

Overall, latency time to enter the novel environment did not differ among treatments $\left(\chi^{2}=0.2536, p=0.8809\right)$, and also males and females did not differ in their exploration tendency $\left(x^{2}=0.0045, p=0.9467\right)$.

Habitat preference in the novel environment differed among treatments $\left(x^{2}=6.5129, p=0.0385\right)$, with fish from the F1 condition having a higher preference for the sheltered area compared with control fish (Figure 2A). Sexes differed significantly in habitat preference $\left(\chi^{2}=10.0152, p=0.0015\right)$, with females spending more time in the sheltered area compared with males.

\section{Open field test}

Overall, total distance moved did not differ among treatments $\left(\chi^{2}=0.8052, p=0.6686\right)$, nor did sexes differ in activity $\left(\chi^{2}=0.0881, p=0.7667\right)$.

TABLE 1: Behavioral response variables/behavioral test ${ }^{a}$

\begin{tabular}{lc}
\hline Behavioral test & Behavioral response \\
\hline Emergence & Latency time to enter novel environment (log) \\
Habitat choice & Total distance moved \\
Open field & $\begin{array}{c}\text { Number of times the fish entered centrum (log }+1) \\
\text { Latency time to enter centrum for the first time (log) } \\
\text { Cumulative duration in centrum (log }+1)\end{array}$ \\
Habitat choice & Habitat choice \\
Life skills & Latency time to feed before attack (double log) \\
& Latency time to resume feeding (log) \\
& Time until movement after attack (log)
\end{tabular}

${ }^{\mathrm{a}}$ To meet model assumptions, variables were transformed (indicated in parentheses) except for habitat choice and total distance moved. 

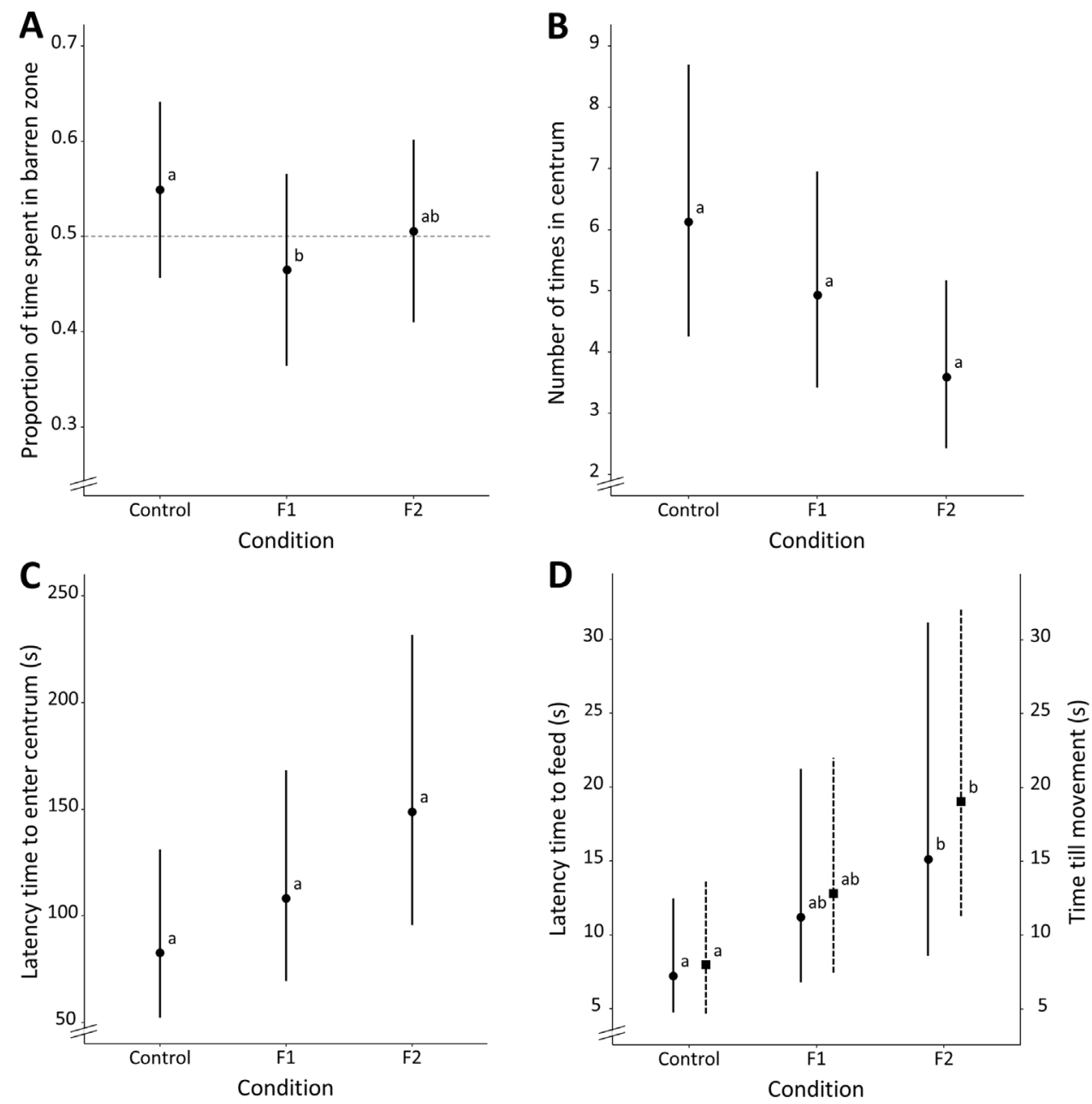

FIGURE 2: Average behavioral response for control fish, fish exposed to $0.5 \mu \mathrm{g} / \mathrm{L}$ fluoxetine (F1) and $5 \mu \mathrm{g} / \mathrm{L}$ fluoxetine (F2). (A) Habitat preference in the emergence test setup, with smaller values indicating a higher preference for the sheltered zone as opposed to the open, barren zone of the arena. (B) Number of times the fish entered the centrum of the open field test setup. (C) Latency time (in seconds) to enter the centrum zone of the open field arena for the first time. (D) Latency time to feed (in seconds) before simulated predator attack (circles and solid lines) and time until movement (in seconds) after simulated predator attack (squares and dashed lines) in the life skills test setup. All behavioral response variables are presented in original scale. Whiskers delineate the upper and lower 95\% confidence limit. Letters indicate significant differences based on Tukey-corrected post hoc tests.

Although overall the number of times that fish entered the centrum was generally lower under increasing fluoxetine concentrations, this was not significant $\left(\chi^{2}=5.8944\right.$, $p=0.0525$; Figure 2B). Also, there was a trend for a higher latency time to enter the centrum with an increasing concentration of fluoxetine (Figure $2 \mathrm{C} ; \chi^{2}=4.6428, p=0.0981$ ). Sexes did not differ in the number of times fish entered the centrum $\left(\chi^{2}=0.0329, p=0.8561\right)$ nor in latency time to enter the centrum (for the first time; $\chi^{2}=0.0217, p=0.8830$ ).

Cumulative duration spent in the centrum did not differ among treatments $\left(\chi^{2}=3.5750, p=0.1674\right)$, or between sexes $\left(x^{2}=0.0346, p=0.8525\right)$.

\section{Habitat choice test}

Habitat preference did not differ among treatments $\left(\chi^{2}=2.4846, p=0.2887\right)$. Sexes differed in habitat preference $\left(\chi^{2}=4.5772, p=0.0324\right)$, with females having a higher preference for the sheltered area compared with males.

\section{Life skills test}

Overall, fluoxetine exposure did not impact the latency time to feed before $\left(\chi^{2}=5.8910, p=0.0526\right)$ or after $\left(\chi^{2}=4.3180\right.$, $p=0.1154)$ the simulated predator attack. Although the overall model result is only marginally significant, post hoc analysis revealed that fish from the F2 condition have a significantly higher latency time to feed before a simulated attack compared with fish from the control condition (Figure 2D). After a simulated predator attack, a trend was observed for a higher latency time to resume feeding with increasing fluoxetine concentration (Supplemental Data, Figure S1). Sexes did not differ in latency time to feed before $\left(\chi^{2}=0.1376, p=0.7107\right)$ or after $\left(\chi^{2}=0.0088, p=0.9254\right)$ the simulated predator attack.

Overall, the time until movement after a simulated predator attack differed among treatments $\left(\chi^{2}=7.9736, p=0.0186\right)$, with F2 fish waiting longer before resuming activity compared with control fish (Figure 2D). The time until movement after a 
simulated predator attack did not differ between sexes $\left(\chi^{2}=0.2005, p=0.6543\right)$.

\section{Fish condition}

Fish condition, measured as body width to size ratio, did not differ among trials $\left(\chi^{2}=1.1259, p=0.5695\right)$ or treatments $\left(\chi^{2}=0.9123, p=0.6337\right)$, nor was the effect of trial dependent on treatment $\left(\chi^{2}=6.5529, p=0.1615\right)$. The width to size ratio differed between sexes $\left(\chi^{2}=3.8959, p=0.0484\right)$, with males having a smaller width to size ratio than females.

\section{DISCUSSION}

Overall, the present study shows the presence of fluoxetineinduced alterations in feeding behavior, habitat choice, and antipredator response of $N$. furzeri individuals. However, with the exception of habitat choice in a novel environment, these effects only emerged at a 10-fold higher concentration of fluoxetine than that typically reported in the environment. In contrast to our hypotheses, spontaneous activity, boldness, and exploration behavior were not impacted by fluoxetine exposure.

Although fluoxetine has been shown to impact basic behavioral traits including activity and boldness, even at concentrations as low as $0.3 \mu \mathrm{g} / \mathrm{L}$, in several fish species (Barry 2013; Brodin et al. 2014; Dzieweczynski et al. 2016b), such effects could not be entirely confirmed for $N$. furzeri in our study. Our results do show, however, that feeding behavior, habitat choice, and antipredator response of $N$. furzeri are directly impacted by chronic fluoxetine exposure. For instance, fish that were exposed to $5 \mu \mathrm{g} / \mathrm{L}$ fluoxetine exhibited a higher latency time to initiate feeding and to resume feeding after a simulated predator attack (trend) compared with control fish. Because increased latency time to feed was not associated with a reduction in body width to length ratio in the present study, a higher latency time could reflect a decrease in the propensity to take risks. This could be true given that energy intake is known to often trade off against predation risk (Lima et al. 1985). In favor of this hypothesis, fluoxetine-exposed fish waited longer before resuming activity after a simulated predator attack, possibly indicating decreased boldness due to fluoxetine exposure. Alternatively, and nonmutually exclusively, these results could also be a reflection of a decrease in appetite: fluoxetine is known to have anorexigenic properties (Halford et al. 2005). Conners et al. (2009), for instance, showed a reduced growth of African clawed frog (Xenopus laevis) tadpoles after fluoxetine exposure and argued that this effect could be driven by reduced food intake. Whether the observed effect on feeding behavior is due to a decrease in appetite or a reduced propensity to take risks should be the subject of further investigation. Finally, although fish that were exposed to fluoxetine exhibited a higher preference for the sheltered area in a novel environment (emergence test), this effect was only present in fish exposed to $0.5 \mu \mathrm{g} / \mathrm{L}$ fluoxetine and could not be replicated in a familiar environment (habitat choice test). Whether this result is indeed biologically meaningful, reflects a false positive, or is due to a differential feeding status between the 2 tests (fish were not fed for $24 \mathrm{~h}$ before the emergence test) remains to be confirmed. Surprisingly, responses to fluoxetine exposure were the opposite of what was hypothesized. Despite the anxiolytic properties of fluoxetine, N. furzeri displayed more risk-averse behavior in response to fluoxetine exposure in the present study. Similar findings on the behavior-modulating impact of fluoxetine exposure in fish have been reported in the literature. For instance, Siamese fighting fish (Betta splendens) were less bold (Dzieweczynski et al. 2016a) and less exploratory (Dzieweczynski et al. 2016b) after fluoxetine exposure. Gaworecki and Klaine (2008) showed that hybrid striped bass (Morone saxatilis $\times M$. chrysops) exhibited a decrease in ability to capture prey in response to fluoxetine treatment. A similar decrease in ability to capture prey after fluoxetine exposure was demonstrated in fathead minnow (Pimephales promelas; Weinberger and Klaper, 2014). In another study, wild guppies (Poecilia reticulata) were found to wait longer before resuming activity after a simulated predator attack and spent more time under plant cover (Saaristo et al. 2017). Although the effects of fluoxetine exposure on behavioral expression in nontarget organisms has received ample attention in the literature, the results are diverse and the underlying behavioral mechanism of action through which fluoxetine exerts its effect on fish remains poorly understood. Underlying mechanisms could include general motor sedation or a decreased arousal to external stimuli (Eisenreich and SzaldaPetree, 2015). Future research is needed to improve our understanding of the fluoxetine-induced behavioral effects reported in literature.

Behavioral ecotoxicology is gaining in popularity, especially with regard to detecting the effects of pharmaceutical pollution, not only because a multitude of pharmaceutical compounds are specifically designed to induce behavioral alterations but also because behavioral endpoints are generally more sensitive compared with traditional endpoints in ecotoxicology (Robinson 2009; Melvin and Wilson 2013; Sumpter et al. 2014). Ecologists and ecotoxicologists have increasingly emphasized the importance of ecotoxicological tests that take natural conditions into better consideration and stress the need for realistic exposure tests to further increase the ecological validity and reliability of ecological risk assessments (Arnold et al. 2014; Backhaus 2014). For instance, the impact and implications of pharmaceutical exposure for wildlife and ecosystems over ecologically relevant time periods remain poorly studied (Fent et al. 2006; Arnold et al. 2014). Moreover, multigenerational setups represent an even higher level of realism compared with chronic toxicity tests that are restricted to one generation. Such tests are particularly relevant because effects of pollutants may only emerge after several generations of exposure or organisms could adapt to the situation and become less sensitive (Goussen et al. 2013; Parker 2016). Fluoxetine, for instance, has recently been shown to induce chromatin changes in "brain reward regions" leading to epigenetic inhibition of behaviorally relevant gene expression (Robison et al. 2014). Accordingly, parental exposure is likely to have consequences for future generations through (transgenerational) epigenetic inheritance, which makes multigenerational testing highly relevant (Parker 2016). The short generation time of $N$. furzeri allows for relatively time-efficient whole-life and 
multigenerational setups to study the impact of pharmaceutical exposure in vertebrate nontarget organisms.

In addition to the major challenge of ecological validity for behavioral ecotoxicology, maximizing test-retest reliability is also of pivotal importance to the field (Parker 2016). Although there is a vast body of literature on the effects of fluoxetine on fish species, the results from these studies are highly diverse, implying that the potency of fluoxetine is variable (Sumpter et al. 2014). Some of these studies report fluoxetine-induced behavioral effects at levels within the $\mathrm{g} / \mathrm{L}$ to $\mu \mathrm{g} / \mathrm{L}$ range (Kohlert et al. 2012; Lynn et al. 2016), whereas others report that even concentrations as low as $\mathrm{ng} / \mathrm{l}$ or $\mathrm{pg} / \mathrm{L}$ can induce differential behavioral expression (Dzieweczynski and Hebert 2012; Barry 2013; Sumpter et al. 2014). Therefore, despite the vast amount of studies that have examined the impact of fluoxetine exposure on aquatic organisms, it remains impossible to reach any consensus on the actual environmental risks of the compound. Sumpter et al. (2014) ascribed the divergence in the literature in large part to the lack of high-quality reproducible research using standard endpoints. Not only is reproducibility fundamental to good scientific practice, it is also essential to ensure reliable risk assessments. Repeatability measures per behavioral endpoint, measured as the between-individual variance in behavioral expression over the sum of between-individual and residual variance, can serve as a first indication for test-retest reliability (Wolak et al. 2012). All behavioral measures in the present study system were shown to be repeatable, as reported by Thoré et al. (2018).

Generally, reliability trades off against ecological validity (Carter et al. 2013; Parker 2016). Thus reaching an equilibrium to maximize both reliability and validity is believed to be one of the challenges in ecotoxicology (Parker 2016). To this end, standardized (reproducible) ecotoxicological tests that allow for testing over ecologically relevant time periods are pivotal, especially for (pseudo-)persistent contaminants such as pharmaceuticals. However, such tests should be time and cost efficient. Traditional model organisms such as zebrafish (Danio rerio) do not allow for this because of their slow life cycle and long lifespan of up to $5 \mathrm{yr}$ (Harel et al. 2015). A standardized ecotoxicological test, based on sensitive, ecologically relevant behavioral endpoints in the model organism $N$. furzeri, has high potential; the use of $N$. furzeri combines the advantages of traditional fish model organisms with the benefit of a shortgeneration time. This allows for whole-life and even multigenerational studies at a reasonable monetary and time cost. In addition to high reliability and ecological validity, a sensitive and standardized test for $N$. furzeri could reduce laboratory animal suffering whereas increased experimental reproducibility would avoid redundant duplication (Parker 2016) and add to a reduction in numbers of laboratory animals.

\section{CONCLUSIONS AND FUTURE PERSPECTIVES}

Behavioral endpoints should be incorporated into ecotoxicological testing to increase ecological realism (Pyle and Ford 2017). However, standardized tests are lacking and current ecotoxicity tests are not suitable to detect specific pharmacological effects. The results of our study indicate that fluoxetine may alter ecologically relevant behavior of the promising model organism N. furzeri. Although behavioral alterations can have important ecological consequences, and although the behavioral endpoints examined are known to be of high ecological relevance in fish, such effects still need to be related quantitatively to environmental protection goals before they can be used as endpoints in environmental risk assessments. This is a major goal of future research. Standardized behavior-based tests with $N$. furzeri could substantially improve the reliability and ecological validity of ecotoxicology. Future efforts should develop this potential and fuel the launch of a reproducible standard test that meets the need for ecological validity, specifically with regard to whole-life or multigenerational setups. A crucial step will be to establish individual variability in behavioral endpoints and to examine how environmental conditions affect baseline behavioral expression (Sumpter et al. 2014). Individual-based studies over ecologically relevant time periods will allow us to unravel and account for individual behavioral variation (Parker 2016) and will be of primary importance to elucidate behavioral expression with relation to underlying physiological traits, life-history expression, and development (Clutton-Brock and Sheldon 2010). Furthermore, a standardized behavior-based test using $N$. furzeri could easily be combined with systematic environmental heterogenization in an attempt to improve reliability even further (Richter et al. 2010; Parker 2016). The unique life-history of $N$. furzeri along with the readily available biomedical and ecological background will drive further advances in behavioral ecotoxicology.

Acknowledgment-The present study was supported by Fonds Wetenschappelijk Onderzoek-Vlaanderen (grants 1S30518N and $12 \mathrm{~F} 0716 \mathrm{~N}$ to E.S.J. Thoré and T. Pinceel, respectively) and by the Excellence Center Eco- and Socio-Evolutionary Dynamics (grant PF/10/007 to C. Philippe). We are grateful to M. Reichard and coworkers for providing the parental fish for this project. We furthermore thank the reviewers for their constructive comments on the manuscript.

Data Accessibility-Data pertaining to this manuscript are deposited in FigShare (https://doi.org/10.6084/m9.figshare. 7418033.v1).

\section{REFERENCES}

Ansai S, Hosokawa H, Maegawa S, Kinoshita M. 2016. Chronic fluoxetine treatment induces anxiolytic responses and altered social behaviors in medaka, Oryzias latipes. Behav Brain Res 303:126-136.

Arnold KE, Brown AR, Ankley GT, Sumpter JP. 2014. Medicating the environment: Assessing risks of pharmaceuticals to wildlife and ecosystems. Philos Trans R Soc B 369:20130569.

Backhaus T. 2014. Medicines, shaken and stirred: A critical review on the ecotoxicology of pharmaceutical mixtures. Philos Trans $R$ Soc $B$ 369:20130585.

Barry MJ. 2013. Effects of fluoxetine on the swimming and behavioural responses of the Arabian killifish. Ecotoxicology 22:425-432.

Brodin T, Piovano S, Fick J, Klaminder J, Heynen M, Jonsson M. 2014. Ecological effects of pharmaceuticals in aquatic systems-Impacts through behavioural alterations. Philos Trans $R$ Soc B 369:20130580. 
Carter AJ, Feeney WE, Marshall HH, Cowlishaw G, Heinsohn R. 2013. Animal personality: What are behavioural ecologists measuring? Biol Rev 88:465-475.

Cellerino A, Valenzano DR, Reichard M. 2015. From the bush to the bench: The annual Nothobranchius fishes as a new model system in biology. Biol Rev 91:511-533.

Clutton-Brock T, Sheldon BC. 2010. Individuals and populations: The role of long-term, individual-based studies of animals in ecology and evolutionary biology. Trends Ecol Evol 25:562-573.

Conners DE, Rogers ED, Armbrust KL, Kwon J, Black MC. 2009. Growth and development of tadpoles (Xenopus laevis) exposed to selective serotonin reuptake inhibitors, fluoxetine and sertraline, throughout metamorphosis. Environ Toxicol Chem 28:2671-2676.

D'Angelo L. 2013. Brain atlas of an emerging Teleostean model: Nothobranchius furzeri. Anat Rec 296:681-691.

Dell'Omo G. 2002. Behavioural Ecotoxicology. John Wiley \& Sons, Hoboken, $\mathrm{NJ}$, USA.

Di Cicco E, Terzibasi Tozzini E, Rossi G, Cellerino A. 2011. The short-lived annual fish Nothobranchius furzeri shows a typical teleost aging process reinforced by high incidence of age-dependent neoplasias. Exp Gerontol 46:249-256.

Dzieweczynski TL, Hebert OL. 2012. Fluoxetine alters behavioral consistency of aggression and courtship in male Siamese fighting fish, Betta splendens. Physiol Behav 107:92-97.

Dzieweczynski TL, Campbell BA, Kane JL. 2016a. Dose-dependent fluoxetine effects on boldness in male Siamese fighting fish. J Exp Biol 219:797-804.

Dzieweczynski TL, Kane JL, Campbell BA, Lavin LE. 2016b. Fluoxetine exposure impacts boldness in female Siamese fighting fish, Betta splendens. Ecotoxicology 25:69-79.

Eisenreich BR, Szalda-Petree A. 2015. Behavioral effects of fluoxetine on aggression and associative learning in Siamese fighting fish (Betta splendens). Behav Proc 121:37-42.

Fent K, Weston AA, Caminada D. 2006. Ecotoxicology of human pharmaceuticals. Aquat Toxicol 76:122-159.

Gaworecki KM, Klaine SJ. 2008. Behavioral and biochemical responses of hybrid striped bass during and after fluoxetine exposure. Aquat Toxicol 88:207-213.

Goussen B, Parisot F, Beaudouin R, Dutilleul M, Buisset-Goussen A, Péry AR, Bonzom JM. 2013. Consequences of a multi-generation exposure to uranium on Caenorhabditis elegans life parameters and sensitivity. Ecotoxicology 22:869-878.

Grégoir AF, Philippe C, Pinceel T, Reniers J, Thoré ESJ, Vanschoenwinkel B, Brendonck L. 2017a. Life stage dependent responses to desiccation risk in the annual killifish Nothobranchius wattersi. J Fish Biol 91:880-895.

Grégoir AF, Thoré ESJ, Philippe C, Pinceel T, Brendonck L, Vanschoenwinkel B. 2017b. Squeezing out the last egg-Annual fish increase reproductive efforts in response to a predation threat. Ecol Evol 2017:1-9.

Gunnarsson L, Jauhiainen A, Kristiansson E, Nerman O, Joakim Larsson DG. 2008. Evolutionary conservation of human drug targets in organisms used for environmental risk assessments. Environ Sci Technol 42:5807-5813.

Gusmão R, Quintao S, McDaid D, Arensman E, Van Audenhove C, Coffey C, Värnik A, Värnik P, Coyne J, Hegerl U. 2013. Antidepressant utilization and suicide in Europe: An ecological multi-national study. PLoS One 8: e66455.

Halford JC, Harrold JA, Lawton CL, Blundell JE. 2005. Serotonin (5-HT) drugs: Effects on appetite expression and use for the treatment of obesity. Curr Drug Targets 5:201-213.

Harel I, Benayoun BA, Machado B, Singh PP, Hu CK, Pech MF, Valenzano DR, Zhang E, Sharp SC, Artandi SE, Brunet A. 2015. A platform for rapid exploration of aging and diseases in a naturally short-lived vertebrate. Cell 160:1013-1026.

Kohlert JG, Mangan BP, Kodra C, Drako L, Long E, Simpson H. 2012. Decreased aggressive and locomotor behaviors in Betta splendens after exposure to fluoxetine. Psychol Rep 110:51-62.

Levitis DA, Lidicker WZ, Freund G. 2009. Behavioural biologists don't agree on what constitutes behaviour. Anim Behav 78:103-110.

Lima SL, Valone TJ, Caraco T. 1985. Foraging-efficiency-predation-risk tradeoff in the grey squirrel. Anim Behav 33:155-165.

Loos R, Carvalho R, António DC, Comero S, Locoro G, Tavazzi S, Paracchini B, Ghiani M, Lettieri T, Blaha L, Jarosova B, Voorspoels S, Servaes K,
Haglund P, Lindberg RH, Schwesiq D, Gawlik BM. 2013. EU-wide monitoring survey on emerging polar organic contaminants in wastewater treatment plant effluents. Water Res 47:6475-8487.

Lynn SE, Egar JM, Walker BG, Sperry TS, Ramenofsky M. 2016. Fish on Prozac: A simple, noninvasive physiology laboratory investigating the mechanisms of aggressive behavior in Betta splendens. Adv Physiol Educ 31:358-363.

Melvin SD, Wilson SP. 2013. The utility of behavioral studies for aquatic toxicology testing: A meta-analysis. Chemosphere 93:2217-2223.

Organisation for Economic Co-operation and Development. 1992. Test No. 203: Fish, acute toxicity test. OECD Guidelines for the Testing of Chemicals. Paris, France.

Organisation for Economic Co-operation and Development. 2012. Test No. 229: Fish short term reproduction assay. OECD Guidelines for the Testing of Chemicals. Paris, France.

Parker MO. 2016. Adult vertebrate behavioural aquatic toxicology: Reliability and validity. Aquat Toxicol 170:323-329.

Philippe C, Grégoir AF, Janssens L, Pinceel T, De Boeck G, Brendonck L. 2017. Acute and chronic sensitivity to copper of a promising ecotoxicological model species, the annual killifish Nothobranchius furzeri. Ecotoxicol Environ Saf 144:26-35.

Philippe C, Grégoir AF, Thoré ESJ, Brendonck L, De Boeck G, Pinceel T. 2018a. Acute sensitivity of the killifish Nothobranchius furzeri to a combination of temperature and reference toxicants (cadmium, chlorpyrifos and 3,4-dichloroaniline). Environ Sci Pollut Res 25:10029-10038.

Philippe C, Grégoir A, Thoré E, De Boeck G, Brendonck L, Pinceel T. 2018b. Protocol for acute and chronic ecotoxicity testing of the Turquoise killifish Nothobranchius furzeri. Vis Exp. DOI: 10.3791/57308

Philippe C, Hautekiet P, Grégoir AF, Thoré ESJ, Pinceel T, Stoks R, Brendonck L, De Boeck G. 2018c. Combined effects of cadmium exposure and temperature on the annual killifish Nothobranchius furzeri. Environ Toxicol Chem 37:2361-2371.

Pinceel T, Vanschoenwinkel B, Deckers P, Grégoir A, Ver Eecke T, Brendonck L. 2015. Early and late developmental arrest as complementary embryonic bet-hedging strategies in African killifish. Biol J Linnean Soc 114:941-948

Polačik M, Blažek R, Reichard M. 2016. Laboratory breeding of the short-lived annual killifish Nothobranchius furzeri. Nat Protoc 11:1396-1413.

Pyle G, Ford AT. 2017. Behaviour revised: Contaminant effects on aquatic. Anim Behav Aquat Toxicol 182:226-228.

R Development Core Team. 2016. R: A Language and Environment for Statistical Computing. R Foundation for Statistical Computing, Vienna, Austria.

Reichwald K, Petzold A, Koch P, Downie BR, Hartmann N, Pietsch S, Baumgart M, Chalopin D, Felder M, Bens M, Sahm A, Szafranski K, Taudien S, Groth M, Arisi I, Weise A, Bhatt SS, Sharma V, Krause JM, Schmid F, Priebe S, Liehr T, Gorlach M, Than ME, Hiller M, Kestler HA, Volff JN, Schartl M, Cellerino A, Englert C, Platzer M. 2015. Insights into sex chromosome evolution and aging from the genome of a short-lived fish. Cell 163:1527-1538.

Richter SH, Garner JP, Auer C, Kunert J, Würbel H. 2010. Systematic variation improves reproducibility of animal experiments. Nat Methods 7:167-168.

Robinson PD. 2009. Behavioural toxicity of organic chemical contaminants in fish: Application to ecological risk assessments (ERAs). Can J Fish Aquat Sci 66:1179-1188.

Robison AJ, Vialou V, Sun HS, Labonte B, Golden SA, Dias C, Turecki G, Tamminga C, Russo S, Mazei-Robinson M, Nestler EJ. 2014. Fluoxetine epigenetically alters the CaMKII a promoter in nucleus accumbens to regulate D FosB binding and antidepressant effects. Neuropsychopharmacology 39:1178-1186.

Saaristo M, McLennan A, Johnstone CP, Clarke BO, Wong BBM. 2017. Impacts of the antidepressant fluoxetine on the anti-predator behaviours of wild guppies (Poecilia reticulata). Aquat Toxicol 183:38-45.

Sakowski SA, Lunn JS, Busta AS, Oh SS, Zamora-Berridi G, Palmer M, Rosenberg AA, Philip SG, Dowling JJ, Feldman EL. 2012. Neuromuscular effects of G93A-SOD1 expression in zebrafish. Mol Neurodegen 7:44.

Schneider CA, Rasband WS, Eliceiri KW. 2012. NIH Image to Image J: 25 years of image analysis. Nat Methods 9:671-675.

Sloman KA, McNeil PL. 2012. Using physiology and behaviour to understand the responses of fish early life stages to toxicants. J Fish Biol 81:2175-2198 
Sumpter JP, Donnachie RL, Johnson AC. 2014. The apparently very variable potency of the anti-depressant fluoxetine. Aquat Toxicol 151:57-60.

Terzibasi E, Valenzano DR, Benedetti M, Roncaglia P, Cattaneo A, Domenici L, Cellerino A. 2008. Large differences in aging phenotype between strains of the short-lived annual fish Nothobranchius furzeri. PLoS One 3: e3866.

Thoré ESJ, Steenaerts L, Philippe C, Grégoir A, Brendonck L, Pinceel T. 2018. Individual behavioural variation reflects personality divergence in the upcoming model organism Nothobranchius furzeri. Ecol Evol 8:8448-8457.

Valenzano DR, Benayoun BA, Singh PP, Zhang E, Etter PD, Hu CK, ClémentZiza M, Willemsen D, Cui R, Harel I, Machado BE, Yee MC, Sharp SC, Bustamante CD, Beyer A, Johnson EA, Brunet A. 2015. The African Turquoise killifish genome provides insights into evolution and genetic architecture of lifespan. Cell 163:1539-1554.

Wang AM, Promislow DEL, Kaeberlein M. 2015. Fertile waters for aging research. Cell 160:814-815.
Weinberger J II, Klaper R. 2014. Environmental concentrations of the selective serotonin reuptake inhibitor fluoxetine impact specific behaviors involved in reproduction, feeding and predator avoidance in the fish Pimephales promelas (fathead minnow). Aquat Toxicol 151:77-83.

Winder VL, Pennington PL, Hurd MW, Wirth EF. 2012. Fluoxetine effects on sheepshead minnow (Cyprinodon variegatus) locomotor activity. J Environ Sci Health B 47:51-58.

Wolak ME, Fairbairn DJ, Paulsen YR. 2012. Guidelines for estimating repeatability. Methods Ecol Evol 3:129-137.

Wolf M, Weissing FJ. 2012. Animal personalities: Consequences for ecology and evolution. Trends Ecol Evol 27:452-461.

Wong RY, Oxendine SE, Godwin J. 2013. Behavioral and neurogenomic transcriptome changes in wild-derived zebrafish with fluoxetine treatment. BMC Genom 14:348.

Wourms JP. 1972. Developmental biology of annual fishes. 1. Stages in normal development of Austrolebias myersi Dahl. J Exp Zool 182:143-167. 